\title{
Cadastro ambiental rural como ferramenta de gestão do território: o caso da subproteção da microbacia do Jaurucu/PA
}

\author{
Rural environmental registry as a territory management tool: \\ the case of the watershed Jaurucu/PA
}

\section{Rafaella Baracho Dias ${ }^{1}$ \\ Wellington de Pinho Alvarez² \\ Thiago Silva dos Santos 3}

\begin{abstract}
1 Bolsista do LABIGEO/Faculdade de Engenharia Agronômica, Universidade Federal do Pará, barachoufpa@gmail.com
2 Coordenador do LABIGEO/Faculdade de Geografia, Universidade Federal do Pará, walvarez@ufpa.br

3 Bolsista do LABIGEO/Faculdade de Engenharia Agronômica, Universidade Federal do Pará, thiagogeografiaatm@gmail.com
\end{abstract}

RESUMO: Gerir o território significar disciplinar o uso dos recursos e o Cadastro Ambiental Rural contribui para controle destes usos nas diferentes áreas do país. Assim, a demarcação de áreas como Reserva Legal e Áreas de Preservação Permanente são formas de proteger cursos fluviais e vida animal. A bacia do Jarauaçu tem mais de $70 \%$ de sua área ocupada para uso pastoril e os diversos cursos fluviais, bem como reservas legais são ocupadas por pastagem em mais de $80 \%$ da bacia. Morfologicamente sua declividade apresenta ondulação suave e forte proporcionando processos erosivos que contribuiu para soterramento de nascentes e canais fluviais.

Palavras chave: Curso fluvial. Microbacia. Cadastro Ambiental Rural.

ABSTRACT: Managing the territory means disciplining the use of resources and the Rural Environmental Registry contributes to the control of these uses in different areas of the country. Thus, the demarcation of areas such as Legal Reserves and Permanent Preservation Areas are ways of protecting river courses and animal life. The Jarauaçu basin has over $70 \%$ of its area occupied for pastoral use and the various river courses as well as legal reserves are occupied by pasture in over $80 \%$ of the basin. Morphologically its slope presents smooth and strong ripple providing erosive processes that contributed to the burial of springs and river channels.

Keywords: River course. Watershed. Rural Environmental Registry.

Sumário: Introdução - 1 Metodologia - 2 Resultados e Discussões - Considerações Finais - Referências

\section{INTRODUÇÃO}

Gestão do territorial é processo decisório em que diversos sujeitos pautam diferentes formas de uso, controle e acesso à recursos, por conta disso, o Estado organiza as propostas de gestão. Não obstante, controlar ações, acessos e formas de exploração dos recursos em determinado território é a base da proposta de ordenamento, cuja características atuais se vincula as formas de conexão deste território a reprodução ampliada, identifica por meio de seus nexos (MIRANDA NETO, 2015 e HERRERA, MOREIRA, 2013).

Por efeito, a Política Nacional de Recursos Hídricos, aprovada pela Lei no 9.433, de 8 de janeiro de 1997, determina que as bacias hidrográficas são unidades territoriais que servem para implantação da política nacional de recursos hídricos, significando ser a bacia uma unidade territorial de planejamento e gestão para 
uso dos diferentes recursos. Desta forma, as diferentes bacias hidrográficas brasileira são por conta da referida política, motivo de atenção e controle estatal e coletivo.

Além disso, o controle sobre as formas de usos dos recursos no interior da bacia hidrográfica determinado pela Lei no 12.651, de 25 de maio de 2012, que substituiu o Código Florestal de 1965 fez com que as diferentes propriedades rurais no Brasil fossem obrigadas a gerar registro virtual em base espacial das diferentes formas de uso. A lei determina a proteção de cursos fluviais, nascentes, olhos d'água e lagoa com a demarcação e manutenção das Áreas de Proteção Permanente (APP) conhecidas popularmente como matas ciliares.

Além destas, destaca-se na mesma lei as áreas de Reserva Legal (RL) como espaço destinado a proteção da biodiversidade com a proteção da paisagem. Sobre esta, destaca-se o geossistema como proposta analítica pautado na interdependência e solidariedade em que os diversos componentes se interagem manifestando no todo escalar (RODRIGUEZ, SILVA e VICENS, 2013).

Não por acaso, a proteção de áreas vulneráveis como canais fluviais, declividades e topos de morro são fundamentais, por isso, as APP e RL em imóveis rurais torna-se essencial à manutenção da estabilidade paisagística, entretanto, a supressão vegetal e exposição do solo a Radiação Eletromagnética (REM), pisoteio e chuva potencializam o processo erosivo cuja condução de sedimentos se dá para interior dos canais fluviais, os quais são marcos do ecossistema (RODRIGUEZ, SILVA e VICENS, 2015).

\section{METODOLOGIA}

A microbacia do rio Jaurucu está localizada entre o município de Altamira e Brasil Novo, municípios do Estado do Pará, a maior parte desta microbacia está em Brasil Novo, conforme figura 1. O Jaurucu em todo seu curso é um grande afluente do rio Xingu, alçando este último próximo de seu exultório com o Amazonas.

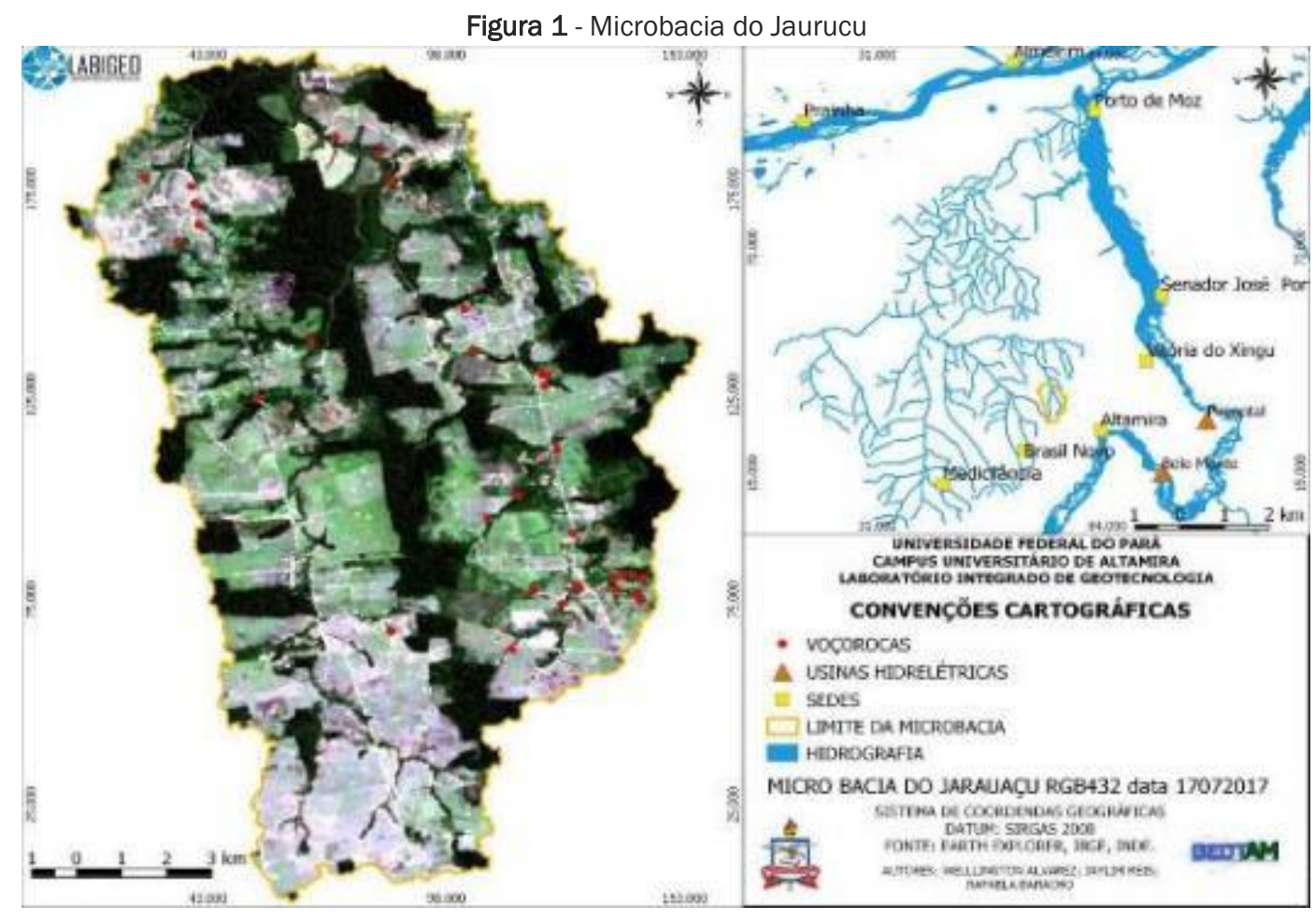


Para obtenção do Modelo Digital de Elevação (DEM) fora feita download na base de dados Earth explorer com valor de 30 metros de resolução espacial, reconhecendo, pois, quem o DEM distingue topo de vegetação do solo, inserindo o cálculo da altimetria, torna-se fundamental extrair a vegetação para então obter o Modelo Digital de Terreno (MDT), em que o primeiro passo fora converter o DEM em nuvem de pontos com a ferramenta r.viewshed no Qgis 3.0.

Em seguida fora baixado a cena 226062, datada de 17 de julho de 2017 do satélite landsat 8 sensor OLI na plataforma Earth explorer, com ela fora calculado o Normalized Difference Vegetation Indexo (NDVI) e por meio da aritmética de bandas, vermelho (banda 4) e infravermelho próximo (banda 5), conforme demonstra a equação:

\section{$N D V I=\frac{(\text { NIR }- \text { Red })}{(N I R+\text { Red })}$}

O NDVI, fora reclassificado com a ferramenta r.reclass Qgis 3.0, separando os valores menores ou iguais a 0.382 que no NDVI significa área com pouca presença de vegetação arbórea, o resultado da reclassificação fora um vetor. Este foi utilizado como máscara para seleção por localização com a nuvem de pontos do DEM, obtendo como resultados os pontos em áreas de solo desnudo ou com vegetação herbácea, sendo estes interpolados com a ferramenta interpolação TIN Qgis 3.0 para obtenção do MDT da microbacia, com ele foi possível obter a declividade com a ferramenta slop Qgis 3.0 qual fora classificada conforme Embrapa (1979).

O NDVI fora fundamental para identificar a presença de vegetação arbórea e solo desnudo na bacia, pois, sendo, bandas espectrais de alta interação com vegetação e solo, o índice contribuiu para análise da bacia. Para análise do uso na bacia, fez-se uso dos dados do projeto terraclass 2014, cena 226062 quais tornou possível a identificação das diferentes classes de uso, para identificação do registro das propriedades rurais e suas respectivas áreas de APP e RL foram realizados download dos dados do Cadastro Ambiental Rural (CAR), onde se obteve dados espaciais das propriedades rurais de Brasil Novo e Altamira, que foram unidos pela ferramenta unir e posteriormente recortados para microbacia com ferramenta recortar Qgis3.0.

\section{RESULTADOS E DISCUSSÕES}

O CAR é uma ferramenta importante de monitoramento dos imóveis rurais. Instituído pela Lei n ${ }^{\circ}$ 12.651/2012 com o objetivo da criação de uma base de dados para controle, monitoramento, planejamento ambiental e combate ao desmatamento. Segundo dados do Ministério do Meio Ambiente (MMA), até 30 de setembro de 2015 , cercam $60 \%$ da área total do Brasil já estavam cadastradas.

O CAR é um cadastro eletrônico nacional obrigatório, que nele constará dados do proprietário, planta georreferenciada do perímetro, contendo áreas de interesse social, APP e RL, dentre outras. Facilitando assim o melhor monitoramento das áreas de uso, que constantemente sofrem com desmatamento e má utilização dos recursos naturais. As propriedades que não estiverem de acordo com a legislação deverão passar um processo de reposição e adensamento de áreas protegidas. A figura 2 mostra com registro no Sistema Nacional de Cadastro Ambiental Rural (SICAR). 


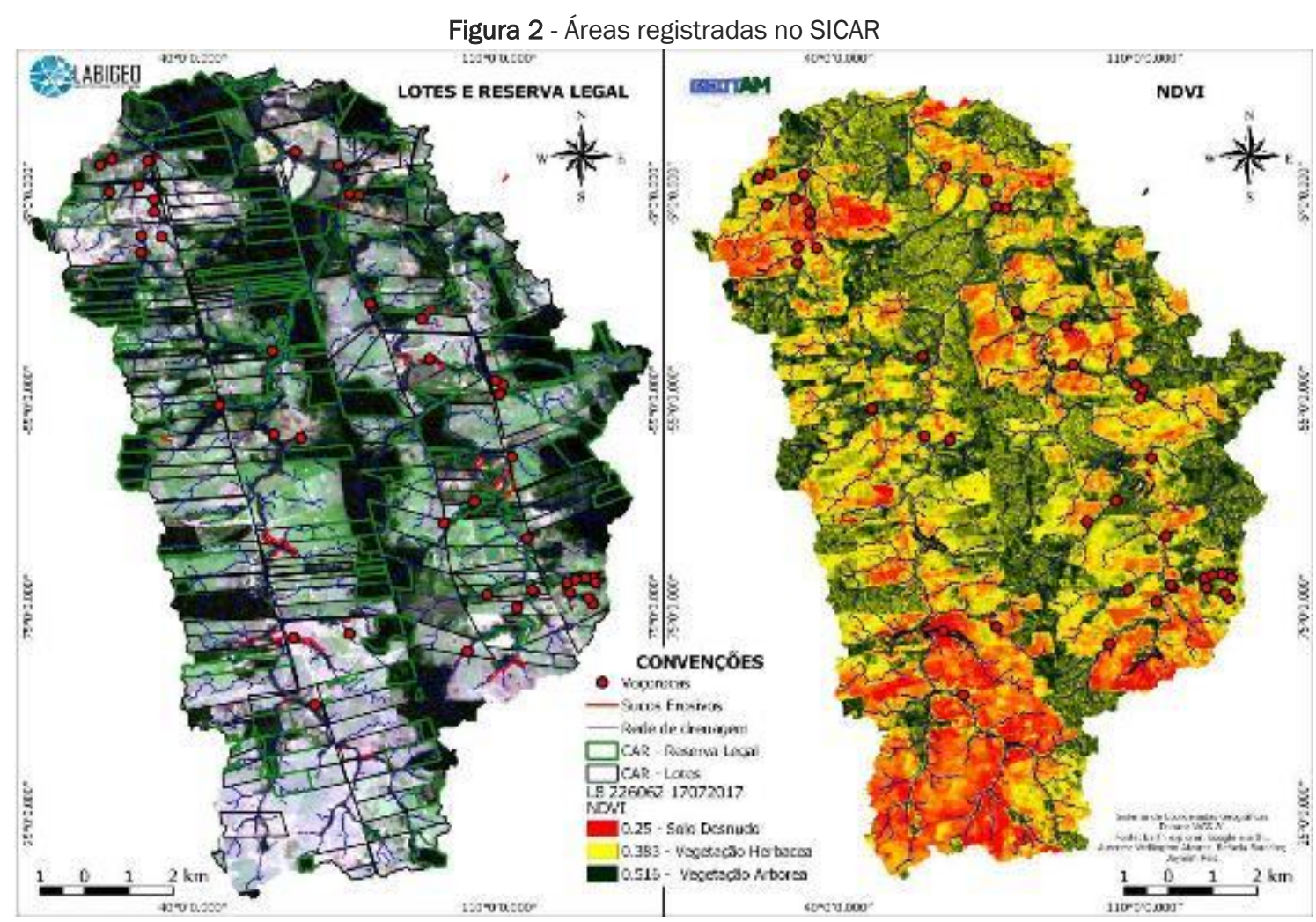

Analisando a figura é possível perceber que cerca de $78 \%$ ou $131.51 \mathrm{Km}^{2}$ da microbacia do Jaurucu está registrada SICAR. Estes imóveis já passaram pelo processo de fiscalização ambiental, mesmo que de forma remota, cuja referência é a análise de dados espaciais. Entretanto, pode-se observar que na área da microbacia do Jaurucu, parte de sua rede de drenagem está desprotegida ou subprotegida, porque não se verifica densidade e contiguidade das APP, da mesma forma, as áreas de RL em sua maioria não são contiguas as APP, que em alguns casos foram suprimidas.

No entanto, a RL é exigida pela legislação de 2012, no Jaurucu, os imóveis rurais são ocupados por pastagem, havendo vasta área de solo desnudo como é perceptível na figura 2. Nesta o NDVI apresenta por contraste a resposta espectral de solo e vegetação, a ponto de estas serem representadas numericamente com valores menores que 0.25 para solo desnudo e maiores que 0.51 para vegetação arbórea.

Nota-se que a presença de solo desnudo é marcante próximo de nascentes dos canais fluviais, em área de maior nível topográfico, que pode cominar prejudicando a bacia. Não por acaso, o não cumprimento pleno da legislação vigente que protege os cursos fluviais de todas as ordens e nascentes contribui em decisivo para o desenvolvimento de problemas relacionados ao uso do solo na bacia em estudo.

Por efeito, a utilização excessiva do solo, a falta da proteção dos cursos fluviais somada a ausência da fiscalização destas áreas, corroboraram para gênese e desenvolvimento de diversos problemas na paisagem da bacia em questão, sendo estes, assoreamento dos rios, soterramento das nascentes e erosões do solo, conforme mostra a figura 3.

Em ambas as imagens da figura 3, é verificável que pela topografia e inclinação do relevo a referida microbacia deve ser alvo de atenção e monitoramento e diminuição do desmatamento e manutenção das áreas protegidas como as APP. Assim, pelas características morfológicas e aspecto a microbacia do Jaurucu é suscetível a problemas a diversos problemas erosivos, como as voçorocas presentes na figura em questão, 
isto porque "as paisagens se adaptam constantemente as modificações promovidas pelas ações humanas" (DE PAULA, 2016, p. 18).

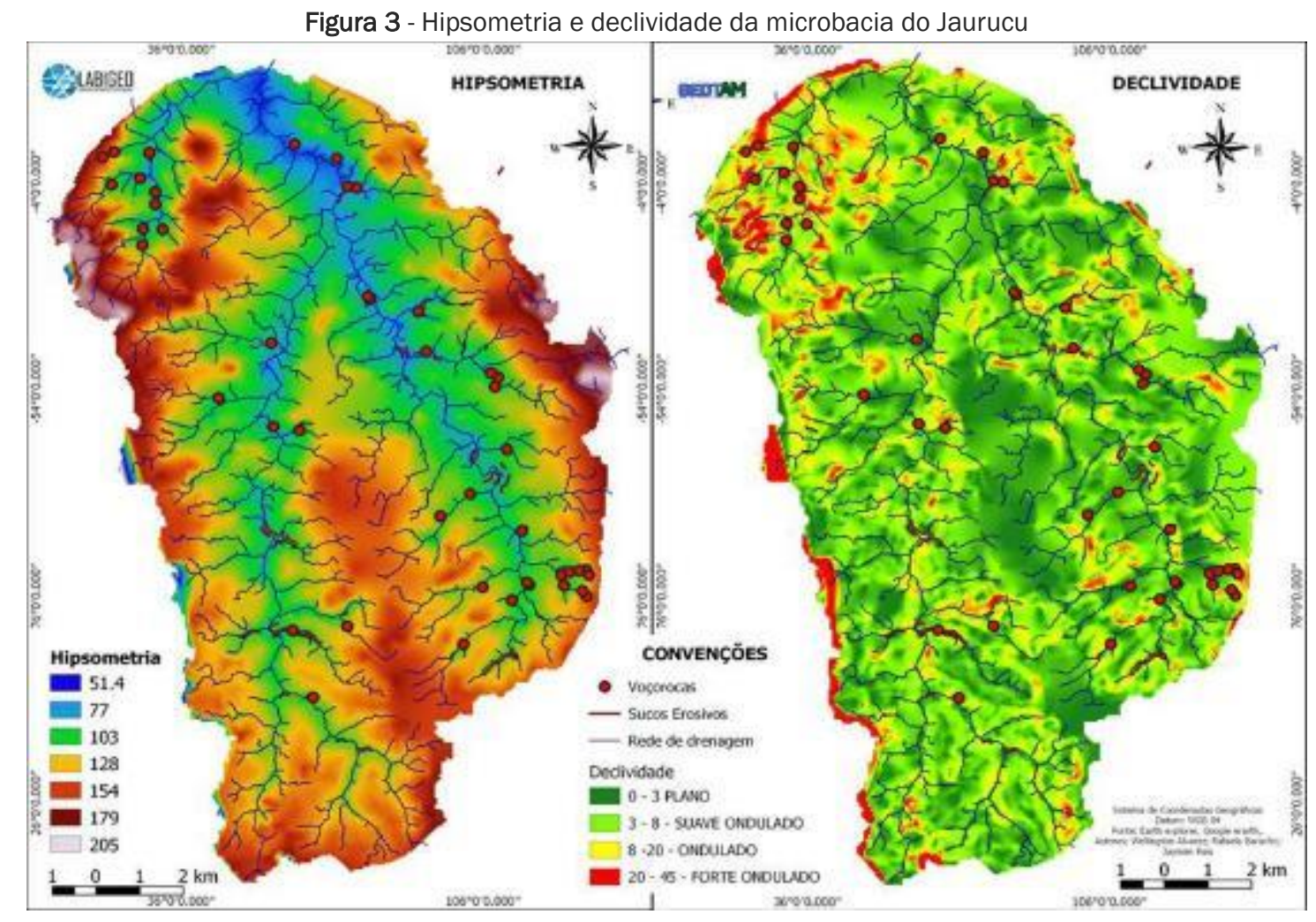

Conforme a figura 4 a área da bacia do Jaurucu em 2014 tinha a fisiologia de sua paisagem (AB' SABER, 1969) constituída em sua maioria por pastagem, indicadas pelas cores em amarelo e alaranjado, principalmente em áreas que são consideradas de APP. As áreas na cor cinza não observadas em 2014, são em 2017, também, áreas de pastagem, como observado na figura 1. A quantidades de áreas de pastagem traduzem a forma predominante de uso, a consolidação da pecuária provocou a incorporação de diversas áreas para a criação de gado, inclusive área protegidas como APP e RL.

O NDVI indicando o uso da APP expressa que a área, em sua maioria, apresenta-se com solo desnudo, identificadas na cor vermelho, com a resposta do NDVI 0,24, havendo fragmentos de vegetação arbórea, qual o NDVI identifica como 0,51. Entretanto, conforme o mapa, verifica-se as cores amarelo e vermelho predominam nas áreas de APP. 
Figura 4 - Usos do solo e NDVI nas APP

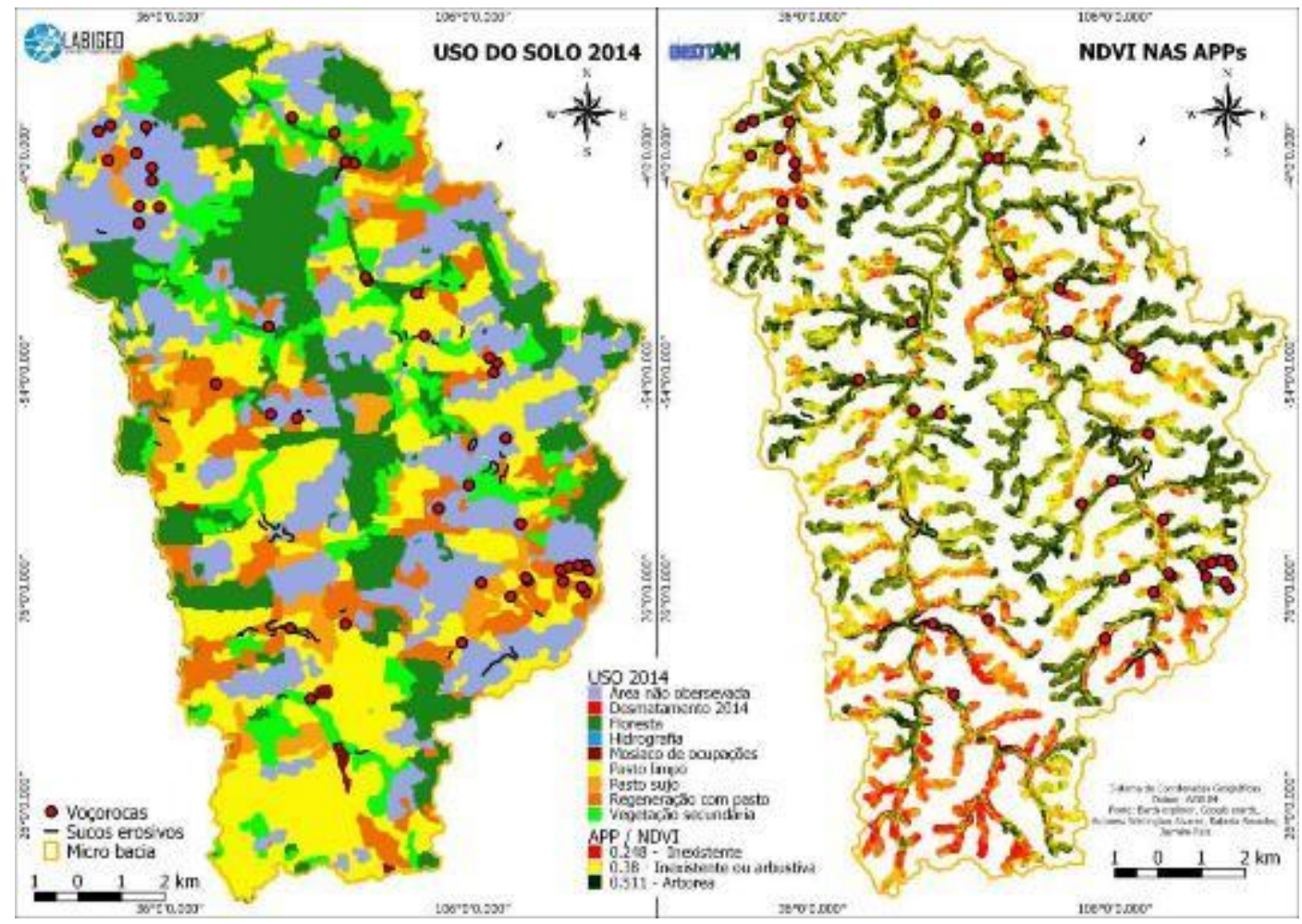

O uso da área da microbacia é empregado, basicamente para a pecuária extensiva, sendo o gado criado solto, cujo pisoteio, falta de matéria organiza e vegetação arbórea acentuam os processos erosivos. Ligada a intensa desnudação do solo e as poucas APP, juntos contribuem no processo de erosão do solo e desenvolvimento das voçorocas na região da microbacia.

As voçorocas são formadas pela combinação de processos erosivos superficiais e subsuperficiais (GUERRA e CUNHA, 2017) e demonstram um desequilíbrio existente na microbacia. O aparecimento desse fenômeno se dá prioritariamente nos cursos fluviais, devido ao uso dessas áreas serem utilizadas para pastagem, como apresentado na figura 5, e sendo esse um fator problemático para a sobrevivência desta microbacia.

Devido à falta de vegetação das APP, o material sedimentar dos processos erosivos são transportados e seu deposito ocorre em áreas mais baixas, sendo estas os canais fluviais. Tornando a existência da mata ciliar de fundamental importância para a proteção da microbacia do Jaurucu. 


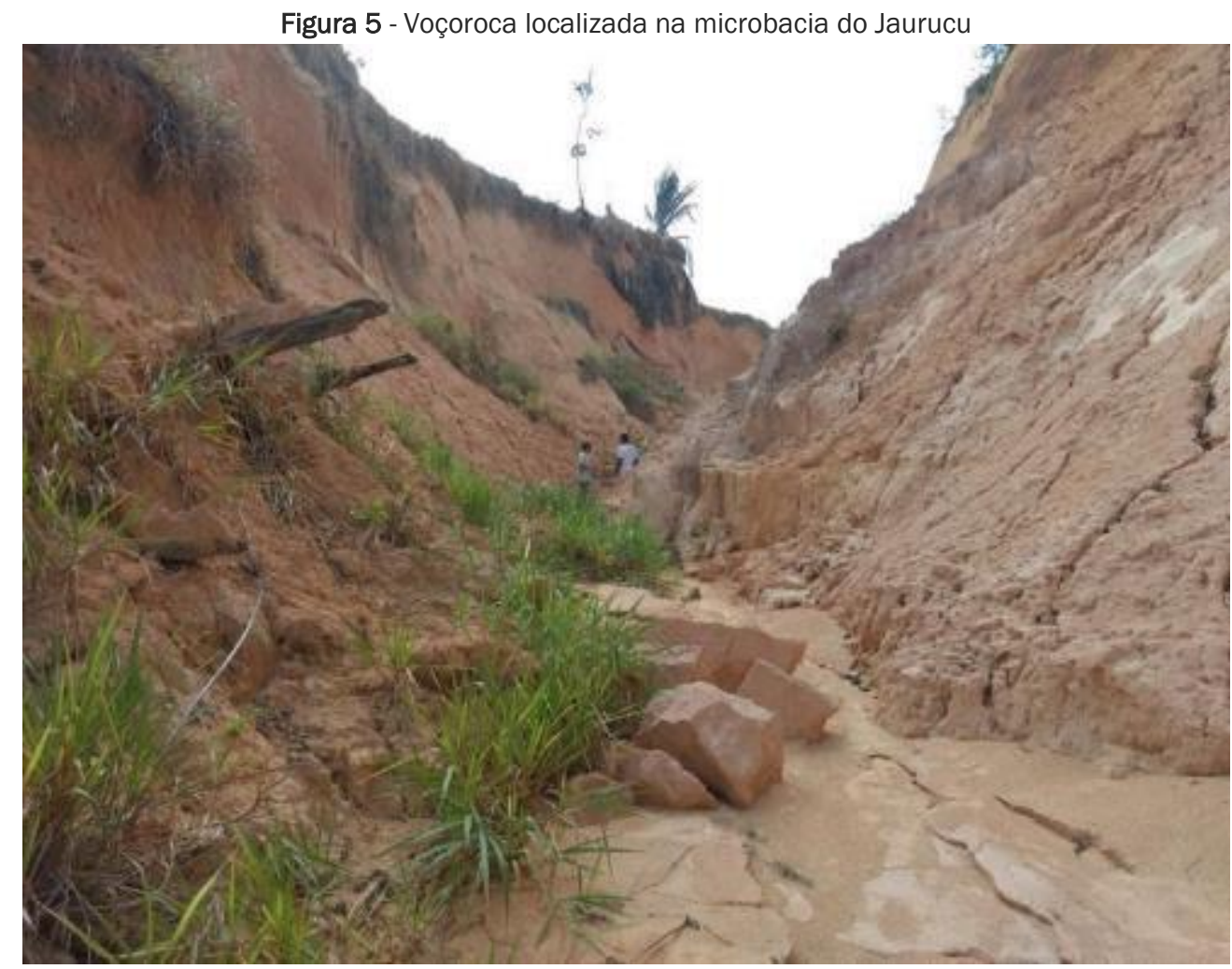

Fonte: Jaylim Reis de Freitas (2018).

A mata ciliar é um tipo de cobertura vegetal presente as margens de corpos hídricos, desempenhando um papel fundamentais, um deles é minimizar a carga de sedimentos carregados por enxurrada ou pelo escoamento superficial rápido, bem como do colapso de encostas.

A qualidade da água dos rios é o resultado da interação entre o clima, a geologia, o solo e a vegetação da bacia hidrográfica. O papel desempenhado pela mata ciliar concorre tanto para diminuir a ocorrência de escoamento superficial, que pode causar erosões, carregando nutrientes e sedimentos para os cursos d'água, quanto desempenhar um efeito de filtragem superficial e subsuperficial dos fluxos de água para os canais (VEIGA, 2003).

Com a presença de mata ciliar nos cursos d'água, ocorre à redução do acúmulo de sedimentos nos rios, sendo uma barreira de impedimento de resíduos poluentes nos corpos hídricos e contribuindo na formação de corredores de conservação da biodiversidade.

$\mathrm{Na}$ busca da redução dos impactos causadas pelo desmatamento nessas áreas, a legislação vigente determina a distância mínima da mata ciliar às margens de rios e nascentes, sendo os canais fluviais da microbacia menores de 10 metros de largura, estes deveriam ter uma proteção da mata ciliar de no mínimo 30 metros. Não se cumprindo a lei na maioria das propriedades localizadas na microbacia.

\section{CONSIDERAÇÕES FINAIS}

Levando em consideração esses aspectos a microbacia do Jaurucu apresenta-se hoje com sérios problemas em sua paisagem devido utilização excessiva do solo e o não cumprimento da legislação em vigor no Brasil em sua plenitude para a proteção dos recursos naturais, por conta disso, exibe-se um cenário grave de desmatamento, podendo assim estar evoluindo para um cenário de colapso da própria bacia hidrográfica e 
da biodiversidade presente.

Diante disso, o CAR se apresenta como uma ferramenta de suma importância na assistência e no controle destas áreas, possuindo o papel de monitoramento e acompanhamento das formas de uso do solo, tornando-se essencial no auxílio da construção de planejamentos ambientais que visa à diminuição dos impactos da utilização do solo, desflorestamento e conflitos de posse.

No entanto, os órgãos responsáveis pelo CAR ainda possuem diversas fragilidades no processo de acompanhamento e fiscalização dos imóveis. Sendo ainda necessário à busca de aperfeiçoamento desse instrumento para que não seja apenas uma forma de organizar o território, mas possuindo efetivamente o potencial de proteção dos recursos naturais, especialmente os recursos hídricos nas áreas protegidas.

\section{REFERÊNCIAS}

AB'SÁBER, A. Um conceito de geomorfologia a serviço das pesquisas sobre o quaternário. Geomorfologia, S. Paulo, lgeog-USP (18), 1969.

BRASIL. Lei $n^{\circ}$ 12.651, de 25 de maio de 2012. Dispõe sobre a proteção da vegetação nativa; altera as Leis nº 6.938, de 31 de agosto de 1981, 9.393, de 19 de dezembro de 1996, e 11.428, de 22 de dezembro de 2006; revoga as Leis $n^{\circ}$ s 4.771, de 15 de setembro de 1965, e 7.754, de 14 de abril de 1989, e a Medida Provisória $n^{\circ}$ 2.166-67, de 24 de agosto de 2001; e dá outras providências. Publicada no Diário Oficial da União, em 28.05.2012.

Lei $n^{\circ}$ 9.433, de 8 de janeiro de 1997. Institui a Política Nacional de Recursos Hídricos, cria o Sistema Nacional de Gerenciamento de Recursos Hídricos, regulamenta o inciso XIX do art. 21 da Constituição Federal, e altera o art. $1^{\circ}$ da Lei $n^{\circ} 8.001$, de 13 de março de 1990, que modificou a Lei $n^{\circ}$ 7.990, de 28 de dezembro de 1989. Publicada no Diário Oficial da União, em 09.01.1997.

GUERR, A, J, T; CUNHA, S, B. Geomorfologia: uma atualização de bases e conceitos. $7^{a}$ ed. Rio de Janeiro - Bertrand Brasil, 2007.

DE PAULA, E, M, Paisagem Fluvial Amazônica: Geoecologia do Tabuleiro do Embaubal - Baixo Rio Xingu / 157 f. Tese (doutorado) - Universidade Federal do Ceará, Centro de Ciências, Programa de Pós-Graduação em Geografia, Fortaleza, 2016. Disponível em: file:///C:/Users/ATMGEOGRAFIA/Downloads/2017_tese_emspaula\%20(1).pdf. Acesso em: 21 ago. 2018.

EMPRESA BRASILEIRA DE PESQUISA AGROPECUÁRIA (EMBRAPA). Serviço Nacional de Levantamento e Conservação de Solos (Rio de Janeiro, RJ). Súmula da Reunião Técnica de Levantamento de Solos. Rio de Janeiro, 1979. 83p. (EMBRAPA-SNLCS. Miscelânea, 1).

HERRERA, J, A; MOREIRA, R, P. Resistência e conflitos sociais na Amazônia Paraense: a luta contra o empreendimento Hidrelétrico de Belo Monte. Campo-território: revista de geografia agrária, v. 8, n. 16, p. 130-151, ago., 2013.

MIRANDA NETO, J, Q. Os nexos de reestruturação da cidade e da rede urbana: o papel da Usina Belo Monte nas transformações espaciais de Altamira-PA e em sua região de influência. Tese. Presidente Prudente - Universidade Estadual Paulista, Faculdade de Ciências e tecnologia. 2015.

RODRIGUEZ, J, M, M; SILVA, E, V; CAVALCANTI, A, P, B. Geoecologia das paisagens: uma visão geossistêmica da análise ambiental. 4.ed. Fortaleza: Edições UFC, 2013.

RODRÍGUEZ, J; SILVA, E; VICENS, R. O legado de sochava. Geographia, 2015. nº 3.

VEIGA, M. P.; MARTINS, S. S.; TORMENA, C. A.; SILVA, O. H. Influência da Mata Ciliar sobre a 
Qualidade da Água do Ribeirão Aurora, no Município de Astorga, Paraná. Arq. Ciên. Vet. Zool. UNIPAR, v. 6, n. 2, p. 149-152, 2003. 